são do "Ocidente familiar e exótico" e de um "Novo estrangeiro". Na análise do primeiro item säo consideradas as "Influências ocidentais" e o questionamento da figura do "Gaijin ou O mito do homem branco no Japäo". No segundo bloco a autora procura ir "Mais além do Ocidente" para retratar o "Anacronismo do gaifin".

Essa primeira parte procura caracterizar uma constante busca de identidade por parte da sociedade japonesa. Caracteriza um esforço social de busca de um modelo próprio de comportamento internacional menos confundido com. os modelos ocidentais, mais precisamente corn o norteamericano, nos anos posteriores a 1945. Segundo Karoline, a importảncia dada pelos japoneses ao Ocidente, ao seu mundo exterior, tem se modificado e se transformado ao longo do tempo não sô em funçäo dos usuais deslocamentos geográficos da cartografia mundial, mas também devido a um certo modo de se relacionar com o outro. Relaçäo esta sempre possivel de variadas formas, mesmo quando nâo säo claras năo só a identidade dos outros como a nossa própria identidade.

A tentativa de delimitaçâo da própria identidade em relaçăo à dos outros, no caso japonês, empreendida pela autora na segunda parte de seu livro, em que apresenta "Os japoneses narrados por eles mesmos: a utilização do discurso insular". No item "Eles e nós" discute a "Invenção da insularidade $e^{*}$ o Postulado da unidade", $e$, no item seguinte, denominado "Novos reconhecimentos", discute "A chamada da Asia" e "O renascimento do espaco príncipal". Em todos estes itens, a autora procura demonstrar a instabilidade da clemarcaçâo da identidade japonesa contraposta ao Ocidente a sua fragilidade quando caracterizada pelos reducionismos e particularismos culturais divulgados de maneira emocional pelos partidários do nihonjin-ron.

Sob a denominaçäo de whonim-ron enquadram-se todos os divulgadores do lapâo, como sendo uma sociedade difenente das demais e calcada em seus particularismos culturais. A tese da singularidade cultural japonesa, embora tenha ganhado grande aceitaçäo popular devido à sua simplicidade argumentativa e a seus fortes contornos emocionais, não tem resistido à veracidade cientifica. Essa não sustentaçăo de uma identidade japonesa calcada em particularidades culturais tem levado um número crescente de japoneses a perceberem que o problema não é afirmar-se uma hipotética singularidade do povo japonès, mas sim dar um sentido à efetiva relaçăo entre o país e o resto do mundo.

A busca de sentido dessa relação è discutida na ültima parte do livro de Karoline, em que "Os japoneses e o cenánio mundial ou $\mathrm{O}$ fim da excef̧ấo nipônica" săo considerados nos itens: "Os estrangeiros na ilha" " $O$ futuro de uma naçöo insular". Nesta parte do livro, a abertura ou o fechamento do Japäo para o resto do mundo é rediscutida a partir de sua forte presença económica no cenário internacional neste final de seculo XX. Näo apenas se apresentam as influências intemacionais sobre o comportamento japonês, sumarizadas na expressãogaintsu (pressoes extemas), como também se menciona a tensăo existente entre modelos de desenvolvimento diferenciados. Ao longo de toda a argumentaçäo, de forma mais implícita que explícita, a autora salienta seu desejo de que o Japăo se assuma como um Estado/naçâo, a exemplo dos paises ocidentais.

Em todo o livro, Karoline Postel-Vinay demonstra profundo conhecimento da sociedade japonesa. Demonstra também grande habilidade acadêmica ao contrapor fatos e ideias sobre o desenvolvimento da sociedade japonesa as percepçóes que os próprios possuem de sì mesmos, ou às percepçōes que seus vizinhos asiáticos ou ocidentais possuem daqueles 126 milhões de habitantes. Esse conhecimento e essa habilidade devem ser conferidos por todos os interessados no desenvolvimento da economia e da política mundiais, como também pelos estudiosos e políticos mais interessados em seus próprios países mas que, quer queiram ou não, possuem alguma forma de inter-relacionamento com a segunda economia do mundo.

Embora o livro tenha sido produzido para o público europeu, em especial, o francês, deve ser examinado por todos os interessados. Espera-se, porém, que esse exame seja realizado da forma mais despretensiosa possível, e náo eurocentrada, como faz a autora, para que a reflexäo estruturada da alteridade permita espaços de pensamento heterogêneos e livres entre dois, sejam estes eu e você ou o Ocidente e o Oriente.

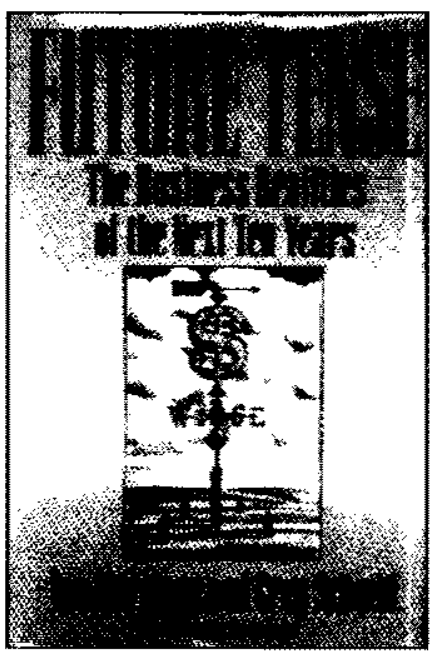

\section{FUTURE TENSE: THE BUSINESS REALITIES OF THE NEXT TEN YEARS}

\section{de IAN MORRISON E GREG SCHMID}

New York: William Morrow and Company, 1994, 304p.

por Cristiano Lúcio de Souza, Bacharel em Administração e Administrador do Instituto Estadual de Desenvolvimento de Recursos Humanos, Belo Horizonte, MG.

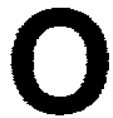
Institute for the Future (IFTF), nos Estados Unidos, é uma organizaçăo de pesquisa que se dedica a observar questōes estratégicas do futuro, analisando grandes volumes de dados e promovendo debates com especialistas. Trata-se de um instituto de pesquisa internaciom nalmente reconhecido que, desde 1968 , tem prestado o ines- 
timável serviço de desenvolver prognósticos para o futuro, a governos, fundaçöes, entidades de interesse público e empresas de grande e pequeno porte, em todo o mundo. Seus clientes incluem mais de 150 grandes empresas, dentre as 500 de Fortune. Agora, o IFTF, pelas mäos de lan Morrison e Greg Schmid, especialistas em planejamento de longo prazo, projeçôes e estorços de planejamento estratégico, produziu uma previsắo de longo prazo, do interesse de todos os homens de negocios, tornando disponivel, pela primeira vez, a qualquer pessoa ou organizaçäo, sua capacidade única para análises e prognósticos.

No prefacio, os autores afirmam: "Ha uma minade de questós que lidderes empresariais, trabalhadores e consumidores $\mathrm{em}$ todo os Estados Unidos estäo debatendo e solucionnndo compelifoidade crescente, penelraço en mercado estrangeiro, downsizing dispensas, consumitor cald wez mas esquitoo, direcáo empresarial e reforma nos beneficios. Mas um fator domina todos eles: um senso peneirante de ansicdade quanto ao futuro. Este e um liwo sobre estas mudancas nos locats de trabalho, que tên produzido wivets crescentes de ansiedade quanto no futuro dos negócios nos ELIA.".

Sáo trazidas à tona trểs temas. O primeiro destes é a importância, para todos no mundo dos negócios, de se prestar atenção ao entendimento, de longo prazo, das forças dirigentes que estăo mudando o ambiente. Se, por um lado, ninguém pode prever o futuro, por outro, aqueles que pensam nele sistematicamente subirão um degrau a mais, definindo oportunidades evitando ameaças. $O$ segundo tema refere-se às respostas administrativas às räpidas mudanças ambientais, as quais, hoje, têm sido parciais e ineficazes. Os modismos administrativos falham ao se ater ao contexto mais amplo de mudança ou às importantes consequiências gerais das açốes dos negócios sobre os empregados, o mercado e a sociedade. Assim, os modismos vêm e văo, às vezes mais exarcebando que resolvendo os problemas fundamentais de longo prazo. As organizaçôes estäo se reestruturando a largos passos, mas, às vezes, picadas pelo ferrão da reengenharia, têm experimentado a falência pela primeira vez. A classe média de hoje, já insegura, tem esse sentimento acentuado ainda mais, quando cada nova onda de downsizing, reengentaria e mudangas no fornecimento externo é anunciada. Todavia, os autores advogam um grande investimento, pelas organizaçöes, em sua capacidade de olhar para frente e desenvolver estrategias visando à prosperidade a longo prazo e a saude e sobrevivência da organizaçâo, dos empregados e da comunidade mais ampla. $\mathrm{O}$ terceiro tema explora os passos que as organizaçoes e as pessoas podem seguir, em resposta ao ambiente de mudança. Os autores não propöem passos simplórios para resolver os problemas, mas mostram como um rico entendimento das forças críticas em direção ao futuro pode ajudar a controlá-lo, em vez de ser controlado por ele.

Assim, em doze capítulos claros, fartamente ilustrados por gráficos e diagramas, os autores investigam as seguintes questöes fundamentais que estăo transformando o clima de quase todos os negócios: consumidores mais velhos e educados; trabalhador inseguro e menos leal; globalização; declínio da lealdade do consumidor à marca; instituicôes à falencia, tais como partidos políticos; público que busca res- ponsabilidade nos negócios; tecnologias disponiveis, Ao examinar estas sete maiores mudanças em potencial para os negócios nos EUA, Morrison e Schmid tomam os abundantes e concretos dados do IFTF e transformam-nos em conselho solido, capaz de levar um homem de negócios ao próximo milênio.

Algums eminentes autores, no entanto, năo são sequer mencionados no livro, como Alvin Toffler, John Naisbitt, Peter F. Drucker, Paul Kennedy, Daniel Bell e Bert Rürup. Ademais, a referência ao Brasil é mínima. Os autores afirmam que, por volta do ano 2010 , o Brasil terá o mesmo número de familias de classe média que a França. As referências aos outros países do Terceiro Mundo săo, também, marginais. Afinal, o livro foi escrito, precipuamente, para os Estados Unidos. Na falta de um similar nacional à altura, toma-se utilissimo em nosso país, tambem sujeito a mudanças.

É verdade que o mundo esta passando por transformaçōes imensas. E nínguém pode dizer exatamente como ele será no século XXI. Muitos futurólogos falam de avanços científicos fantasiosos, que refletem sonhos e näo possibiljdades realistas. Outros observadores, menos arrojados, projetam apenas tendências do que ocorre hoje - os índices de natalidade, por exemplo -, como causas inexoráveis dos problemas futuros. Ambas as cornentes subestimam as dificuldades de se prever o futuro, uma vez que as mudanças são extraordinárias e incertas. As correntes políticas e ideológicas, por exemplo, são demasiadamente complexas e suas características não são facilmente determinadas. Outro exemplo: enquanto proliferam informaçöes e tecnologias de comunicaçāo é cada vez mais difícil se definir a diferença entre tecnologias que rompem os fundamentos e invençoes inúteis. Morrison $\mathrm{e}$ Schmid sabem disso muito bem. Porém, a partir de uma variedade de metodologias, eles tentam oferecer uma âncora contra as forças freqüentemente inexplicáveis e não gerenciáveis que transformam o local de trabalho, o comportamento do consumidor e nosso diaa-dia. Ao colherem dados das vastas tontes globais do IFTF, os autores examinaram questoes criticas momentosas que afetam todo tipo de negócio e criaram uma ferramenta prática que pode ser usada para adaptar os negócios de hoje às realidades futuras.

Morrison e Schmid ensinam a olhar para frente e os benefícios advindos disso. Escrevem no epílogo: "Olhando para a frente, confrontando o futuro ebseroando as rerselaçöes de tendencias, o mundo parece menos ao acaso, emergem padröes, novas ameaças são pevistas e evitadas e novas oportunidades são identificadas e exploradas".

Assim, para todo tipo de executivo ou empreendedor, a leitura de Future Tense poderá fazer uma diferença no ato de planejar os negócios do futuro, de agora até os próxinos dez anos. Esta previsão, com seus dados críticos, poderá permitir entender o impacto de tendências correntes, a fim de que se ajustem os planos para a obtenção de sucessos financeiros no futuro. Para os leitores em geral, poderă alterar completamente a maneira pela qual preparam a si próprios, suas familias e suas atividades para confrontar as mudanças que o futuro próximo muito provavelmente trará consigo. $\beth$ 